\title{
A comparative evaluation of properties of denture base materials processed with different processing methods: a preliminary study
}

\author{
Sangam Bhavana Lahari1, ${ }^{*}$, Srinivas Rao Pottem². Anyam Ram Koti Reddy1, Pavan Kumar Tannamala², \\ Kalamalla A Saran Babu ${ }^{3}$, Vangala R L Manogna4 \\ ${ }^{1}$ Postgraduate Student, ${ }^{2}$ Professor, ${ }^{3}$ Senior Lecturer, Department of Prosthodontics, Narayana Dental \\ College, Nellore, Andhra Pradesh, India. \\ ${ }^{4}$ Research Volunteer, Meharry Dental School, Nashville, Tennessee, USA.
}

\section{N F O R M A T I O N A B S T R A C T}

\section{Article History}

Received $16^{\text {th }}$ July 2021

Received revised 14th August 2021

Accepted 21 ${ }^{\text {st }}$ August 2021

Available online $1^{\text {st }}$ December 2021

\section{K E Y W O R D S}

Heat cure acrylics

Curing

Pot-pressure curing

Flexural strength

Water sorption
Background: The use of the traditional polymerization process of dentures necessitates a lot of time and energy. To depreciate these factors, a different processing method could be studied.

Aim: This study was aimed to evaluate and compare the properties of denture base resin material processed with conventional curing and pressure-pot method.

Materials and methods: A total of 30 specimens with distinct dimensions were fabricated with the denture base materials. The specimens were divided into two groups with 15 each, and they were processed using conventional heat-curing and pressure-pot processing, respectively. Each group is subdivided into three groups with five specimens in each for evaluating flexural strength, water sorption, and residual monomer, respectively. Flexural strength was measured using a 3-point bending test with a Universal testing machine. Water sorption was assessed by measuring the weight of the specimens after immersing them in distilled water. Residual monomer content was evaluated using a UV spectrophotometer. The obtained data were statistically analysed using an independent t-test.

Results: A slight increase in flexural strength was observed in the pressure processed specimens. However, no significant differences $(p=0.131)$ were observed in the flexural strength between the groups. Less water sorption percentage was observed with the pressure processed acrylic resin specimens, and a significant difference $(p=0.047)$ was observed between the groups. A slightly more amount of residual monomer content was seen in the acrylic specimens processed conventionally.

Conclusion: Pressure-pot curing may be used for processing denture base acrylics as it provides properties similar to that of the conventional curing method.

\section{Introduction}

Besides the enormous development of new materials and techniques, the rehabilitation with a removable prosthesis made of polymethyl methacrylate (PMMA) resin has been the preferred material since the 20th century [1]. PMMA

Correspondence: ${ }^{*}$ Corresponding author Email Address: sanghambhavana1313@gmail.com

How to cite this article: Bhavana Lahari S, Pottem SR, Ram Koti Reddy A, Tannamala PK, Saran Babu KA, Manogna VRL. A comparative evaluation of properties of denture base materials processed with different processing methods: a preliminary study. Int J Dent Mater 2021;3(4): 106-111. 
has diverse advantages such as ease of processing, colour matching with the adjacent soft tissues, inexpensive, etc. [2] Polymerization of PMMA can be accomplished in several ways including, chemical, visible light, and heat activation (microwave energy/ hot water bath) [1-3]. Despite the availability of numerous polymerization methods, heat cure polymerization is popularly practiced [4]. The appropriate curing influences the physical and mechanical properties of denture prostheses. Improper curing may cause evaporation of monomer resulting in the formation of internal porosities and weakening the mass.

Numerous studies investigated the effect of different curing techniques on the properties of denture base acrylics. The regular processing time comprises a longer curing cycle i.e., $74^{\circ} \mathrm{C}$ for 8 hours followed by $100^{\circ} \mathrm{C}$ for 1 hour; alternatively, a short curing cycle of $74^{\circ} \mathrm{C}$ for 2 hours followed by $100^{\circ} \mathrm{C}$ for 1 hour [5]. These two curing cycles produce denture prostheses with minimum porosities. However, these two procedures require three to nine hours to complete the polymerization process. Faraj and Ellis (1979) [6] proposed that porosity would emerge in the cured resin only if the monomer's vapour pressure was greater than air pressure at temperatures above 100 degrees Celsius and that this pressure may be more than the denture flask clamping pressure. This clamping pressure is required to adapt the acrylic dough to the master cast during the curing and reduces the thermal shrinkages while polymerization and cooling. Various studies mentioned that the pressure applied to provide metal to metal halves contact during trail closures is in the range of 1500 - 4500 psi. Various studies demonstrated an improved degree of cure and flexural strength when the denture base acrylics were processed with microwave curing under pressure compared to conventional curing methods [7].

Processing acrylic dentures with a pressure cooker is another technique reported in the literature $[3,8]$. The advantage of this technique is that it can be used with the conventional acrylic resin material, and it requires less than one hour to complete the polymerization. However, limited research was available on the influence of pressure cooker processing on the properties of denture base materials. Therefore, this study was designed to evaluate and compare the properties of acrylic materials processed with the conventional and pressure processing methods.

\section{Materials and methods}

A total of 30 specimens were made using the conventional heat-cure denture base material (Dental Products of India, Mumbai, India). Among the 30 specimens, 15 specimens were processed with the conventional curing (group 1) and the remaining were cured with the Pot-pressure method (Group 2).

\subsection{Sample preparation}

A total of 30 wax specimens were made with the modelling wax (The Hindustan Dental Products, India) as per the ISO 20795-1:2008 to evaluate the flexural strength $(65 \times 10 \times 3 \mathrm{~mm})$, water sorption $(10 \times 10 \times$ $1.5 \mathrm{~mm})$, and residual monomer content $(10 \times 10 \times 1.5$ $\mathrm{mm})$.

\subsubsection{Conventional polymerization method}

After the bench curing for about 30 mins/1 hour, the specimens were processed with conventional heat polymerized technique in an acrylizer (Confident A-73, India) at $73^{\circ}$ for 90 minutes and then at $100^{\circ} \mathrm{C}$ for 30 minutes. The acrylic specimens were retrieved by deflasking following the bench cooling for about 30 minutes at room temperature. The excess material from the specimens was trimmed, and finishing and polishing were done.

\subsubsection{Pressure-pot polymerization method}

After the bench curing for about 30 minutes/1 hour, the dental flask was placed in a water-filled pressure pot and the lid was closed with weight in place. The flame was turned on till the first pressure ejection and permitted to cool to room temperature. The lid was opened and deflasked, the specimens were verified, and excess material was trimmed and wet polished.

\subsection{Flexural strength evaluation}

A total of 10 specimens $(n=10)$, which comprises 5 specimens from each group were subjected to a 3 point bending test using the universal testing machine (UTES-40-HGFL, Fuel Instruments and Engineers Pvt Ltd., India) at a crosshead speed of $5 \mathrm{~mm} / \mathrm{min}$ until the specimen fractured. The load at fracture was computed automatically from the universal testing machine.

\subsection{Water sorption evaluation}

A total of 10 specimens $(n=10)$, which comprises 5 specimens from each group, were used for the evalua- 
tion of water sorption. The specimens were weighed by digital analytical weighing balance (Shimadzu ATX 224 , India) instantly after preparation (W1). The specimens were stored in distal water for one week at $37^{\circ} \mathrm{C}$ in an oven. After week, they were removed, and the excess water was shaken off. The specimens were weighed (W2). Then, the specimens were desiccated for 24 hours and the weight (W3) of the specimens were recorded. The percentage of water sorption was calculated using the following formula.

$$
(\mathrm{W} 2-\mathrm{W} 3) / \mathrm{W} 1 \times 100 \text {. }
$$

Where,

W1 is the original weight of the specimen.

W2 is the weight of the specimens after 7days of immersion.

W3 is the weight of the specimens after desiccation.

\subsection{Residual monomer evaluation}

The A total of 10 specimens $(n=10)$, which comprises five specimens from each group, were stored in distilled water for two days at $37^{\circ} \mathrm{C}$. The storing medium of each specimen was collected through a pipette and placed over Nano-drop advanced version of UV spectrophotometer (NanoDrop ${ }^{\mathrm{TM}}$ 2000/2000c Spectrophotometers, ThermoFisher Scientific, USA). The detection was performed under the wavelength of $400 \mathrm{~nm}$, the pipette volume was $0.5 \mu$ l. The values and graphs of both groups were generated digitally.

The obtained data were subjected to statistical analysis using Statistical Package for Social Sciences (SPSS), version 20.0, USA.

\section{Results}

In the present study, an independent t-test was employed to find the significance of flexural strength and percentage of water absorption rate of the acrylic specimens from the groups. The acrylic specimens processed with the pot-pressure method showed a slightly more flexural strength compared to the conventional curing method with a mean flexural strength of 66.23 $\pm 9.27 \mathrm{MPa}$ (Table 1). However, statistically, no significant differences $(p=0.131)$ were observed between the two groups (Table 1).

The percentage of water sorption of acrylic specimens cured with different processing methods is given in table 2 . The acrylic specimens processed with the potpressure method showed the least water sorption
$(0.81 \%)$ compared to the specimens processed with the conventional curing method. Statistically, a significant difference $(p=0.047)$ was observed between the two groups (Table 2).

The residual monomer content of both the groups was plotted in figure 1 . The values had fallen close to each other from both groups. A slightly more amount of residual monomer is observed from the specimens processed with the conventional curing method.

\section{Discussion}

The polymerization of PMMA requires activation of an initiator (benzoyl peroxide), to commence the additive reaction from a first free radical to start the polymerization chain reaction by opening the double bonds of the methyl-methacrylate. The threshold temperature for the generation of free radicals requires more than $60^{\circ} \mathrm{C}$. As the temperature increases, there is a chance for increasing the exothermal polymerization. The methyl-methacrylate monomer boils at $100.8^{\circ} \mathrm{C}$, and at this temperature, the residual monomer evaporates and create porosities in the resin and weakens the mass. To avoid this, the polymerization requires initial processing at a low temperature for a long time to prevent boiling of the monomer. To balance this thermal gradient, the complete polymerization of the denture base at least requires 8 hours at a much slower rate. Therefore, the longer time for the processing is a major disadvantage of the water bath polymerization technique [5].

Although microwave polymerization; which was introduced by Nishii et al. in 1968 [3], takes less than 10 minutes, which claimed as a major advantage and reported with better dimensional stability, transverse strength, less residual monomer content, and porosities. However, microwave polymerization has inherent disadvantages including the usage of special nonmetallic flasks, conventional resins that cannot be used, and expensive [9]. Numerous researchers suggested the usage of a pressure-pot for processing acrylic dentures at a different time and pressure intervals as an alternative [10]. However, adequate research was not focused on the effect of pressure pot processing on the properties of denture base resin materials. Hence, this study was designed to compare the effect of conventional and pressure-pot processing on the flexural strength, water absorption and residual monomer content of commonly used denture base material. 
Table 1: Comparison of flexural strength (MPa) between conventional and pressurepot polymerization methods (one-way ANOVA).

\begin{tabular}{lccccc}
\hline Polymerization methods & $\mathbf{n}$ & Mean \pm Standard deviation & t-value & $\begin{array}{c}\text { Significance } \\
(\boldsymbol{p} \text {-value })\end{array}$ \\
\hline Conventional water bath & 5 & $66.23 \pm 9.27$ & 1.677 & $0.131^{*}$ \\
\hline Pressure polymerization & 5 & $78.92 \pm 14.13$ & & \\
\hline
\end{tabular}

*statistically no significant difference was observed.

Table 2. Comparison of water sorption (\%) between conventional and pressure-pot polymerization methods (one-way ANOVA).

\begin{tabular}{lcccc}
\hline Polymerization methods & $\mathbf{n}$ & Water sorption (\%) & t-value & $\begin{array}{c}\text { Significance } \\
(\boldsymbol{p} \text {-value) }\end{array}$ \\
\hline Conventional water bath & 5 & 1.63 & 0.063 & $0.047^{*}$ \\
\hline Pressure polymerization & 5 & 0.81 & & \\
\hline
\end{tabular}

*statistically significant difference was observed

\section{Figure 1. Residual monomer content of acrylic specimens processed with different} techniques.

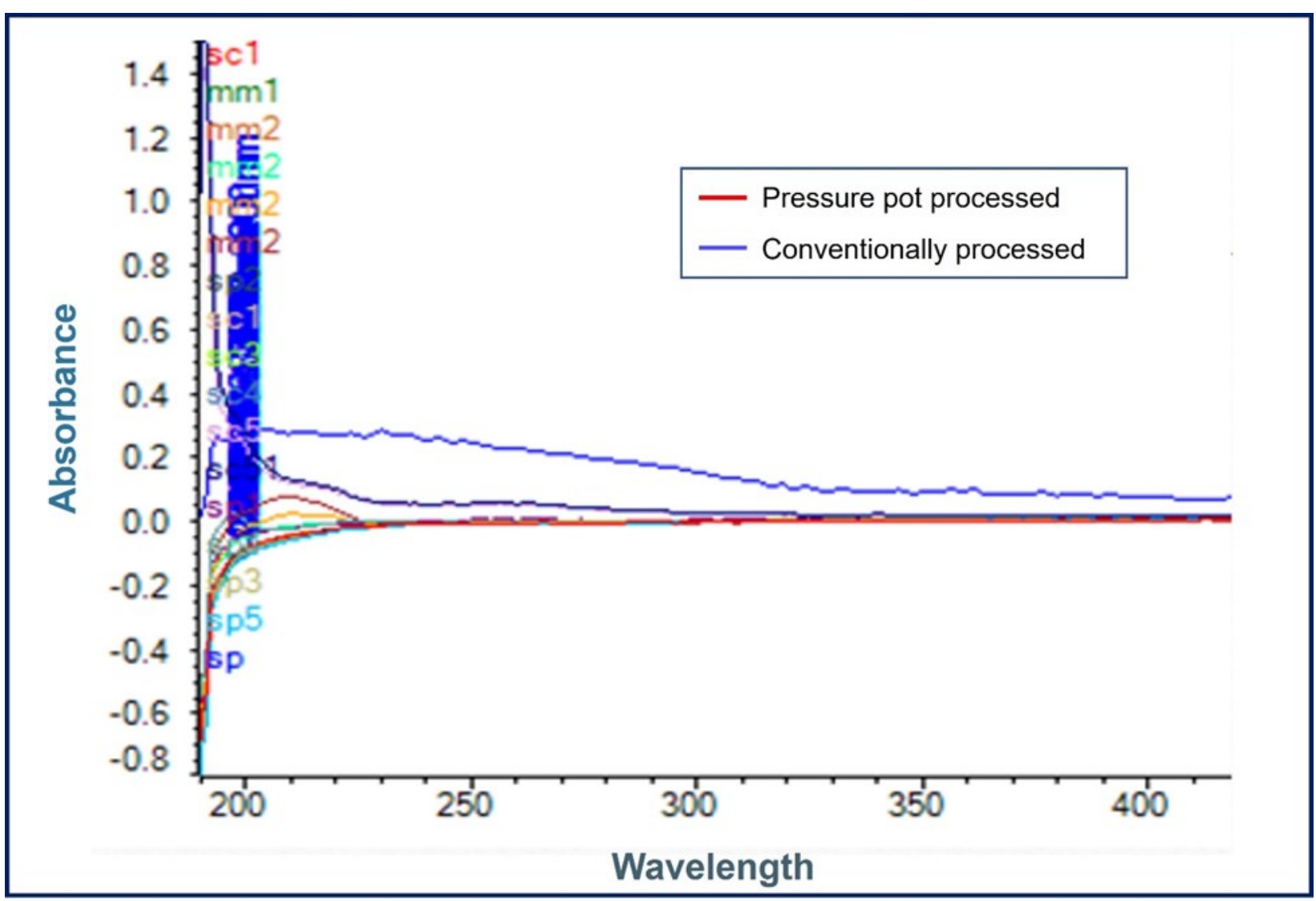


In the present study, the flexural strength was assessed as it reflects the complex stresses applied to the denture during mastication. The pressure-pot processed acrylic specimens exhibited a slightly greater mean flexural strength compared to the conventionally processed acrylic specimens. This slight increase in flexural strength can be attributed to the greater degree of polymerization under higher pressure $(1 / 15 \mathrm{psi})$ in the pressure pot, thereby the boiling point of water rises from $100^{\circ}-121^{\circ} \mathrm{C}$. The hotter steam can transmit its thermal energy around four times the rate of conventional boiling, and pressure can be maintained up to a certain period. An important role played by rising steam pressure is that it is instantly transmitted to the resin dough, possibly accelerating the initial polymerization and reducing the boiling of the monomer and thus preventing the residual monomer and the porosities. Earlier it was thought that the boiling point of monomer at $1520 \mathrm{~mm} / \mathrm{Hg}$ could be much higher than $120^{\circ} \mathrm{C}$. However, Maron and Prutton determined a formula for the boiling point of monomer at this pressure [9-11].

$$
\log 10=\frac{\mathrm{P} 2}{\mathrm{P} 1}=\frac{\mathrm{HV}}{2.30 \mathrm{R}}=\frac{(\mathrm{T} 2-\mathrm{T} 1)}{\mathrm{T} 2 \cdot \mathrm{T} 1}
$$

P2 = pressure under consideration

$\mathrm{P} 1$ = atmospheric pressure

$\mathrm{HV}=$ heat of evaporation (8974.9 in case of methyl methacrylate)

$\mathrm{R}=1.987$ (gas constant in case of methyl methacrylate)

$\mathrm{T} 2$ = boiling point at $\mathrm{P} 2$

$\mathrm{T} 1$ = boiling point at $\mathrm{P} 1$

Using this formula, the boiling point of methyl methacrylate resin was calculated to be $128^{\circ} \mathrm{C}$ at $1520 \mathrm{~mm} \mathrm{Hg}$ in the pressure cooker. This fact supports the hypothesis that pressure plays a significant role in accelerating the initial polymerization.

Acrylic polymers have the ability to absorb water. Further, the presence of porosities in the acrylic mass increases the water sorption capability. The absorbed water pushes the polymer chains apart and weakens the mass [12]. This study demonstrated less amount of water sorption by the acrylic specimens processed with pressure-pot. This is due to the smaller number of porosities in the pressure-pot processed specimens as there must be a greater degree of polymerization. The water sorption results of this study are in accordance with S.V. Bhide et al. [10]. From this study, it is evident that the lesser the water sorption more would be the flexural strength for acrylic dentures.

Inadequate or improper usage of the polymerization cycle leads to a more amount of residual monomer. This residual monomer may be leached into the oral cavity from the denture prosthesis during its service and transported to several parts of the body and exhibits several systemic toxic effects [13]. Therefore, it is necessary to follow an appropriate curing mechanism to enhance the degree of polymerization. Hence, this study also focused on evaluating the residual monomer content of acrylic resin specimens processed with different curing methods. From this study, it was observed that the pressure-pot curing facilitated the maximum conversion of monomer molecules to the polymer by maintaining the temperature under pressure.

This study was focused on evaluating the flexural strength, water absorption and the residual monomer content of the acrylic specimens processed with conventional and pressure-pot curing methods. Further studies may be conducted on evaluating the other physical and mechanical properties of denture base materials processed with the pressure-pot curing method.

\section{Conclusion}

From the results of this study, the following conclusions can be drawn.

1. Both the processing methods do not have a significant effect on the flexural strength of the acrylic resin specimens.

2. The percentage of water sorption was less in the acrylic specimens processed with the pressure-pot technique compared to the specimens processed with conventional methods.

3. From this study, it was observed that the pressurepot processing method had an advantage in terms of decreased processing time and utilization of less energy.

Conflicts of interest: Authors declared no conflicts of interest.

Financial support: None 


\section{References}

1. Alla R, Raghavendra KN, Vyas R, Konakanchi A. Conventional and contemporary polymers for the fabrication of denture prosthesis: part I-overview, composition and properties. Int J Appl Dent Sci. 2015;1(4):82-9.

2. Anusavice KJ. Denture Base Resins, In Philips' Science of Dental Materials. $11^{\text {th }}$ Edition, SAUNDERS, USA, 721-758.

3. Nishii, M. Studies on the curing of denture base resins with microwave irradiation: with particular reference to heat-curing resins. J Osaka Dent Univ. 1968; 2:23-40.

4. Muhammad Sohail Zafar, Prosthodontic Applications of Polymethyl Methacrylate (PMMA): An Update. MDPI journals polymers 2020,12,2299. https:// doi.org/10.3390/polym12102299

5. Xia Chun Ming, Rapid-processing procedure for heat polymerization of polymethyl methacrylate in a pressure cooker with automatic controls. J Prosthet Dent. 1996;76:445-7. https://doi.org/10.1016/S0022-3913 (96)90552-1

6. Faraz SAA, Ellis B. The effect of processing temperature on the exotherm; porosity and properties of acrylic denture base. Brit Dent J 1979;147:209-12. https:// doi.org/10.1038/sj.bdj.4804325

7. Aldoaei EG, Badr NA, Abdel Hamid DM. The effect of curing techniques of denture base resins on strength characteristics under different loading modes. Egypt. Dent. J. 2012;58: 3927-3937.

8. Banerjee R, Banerjee S, Prabhudesai PS, Bhide SV. Influence of the processing technique on the flexural fatigue strength of denture base resins: an in vitro investigation. Ind J Dent Res. 2010;21(3):391-5. https://doi.org/10.4103/0970-9290.70810

9. Undurwade JH, Sidhaye AB. Curing acrylic resin in a domestic pressure cooker: A study of residual monomer content. Quintessence Int 1989;20:123-9.

10. Bhide SV. Assessment of linear dimensional changes in denture base cured twice using fast as well as slow curing cycle and steam pressure curing method: An unpublished thesis; submitted to the University of Mumbai, April 1979.

11. Jadhav R, Bhide SV, Prabhudesai PS. Assessment of the impact strength of the denture base resin polymerized by various processing techniques. Ind J Dent Res 2013;24:19-25. https://doi.org/10.4103/0970-9290.114926

12. Alla RK, Swamy KN, Vyas R, Tiruveedula NB, Raju AM. Physical and mechanical properties of heat activated acrylic denture base resin materials. Research Journal of Pharmacy and Technology. 2018;11 (6):2258-62. https://doi.org/10.5958/0974-360X.2018.00418.3

13. Gosavi SS, Gosavi SY, Alla RK. Local and systemic effects of unpolymerised monomers. Dent Res J. 2010;7(2):82. 